\title{
Squamous Cell Carcinoma Arising in Ungual Lichen Planus: Report and Review
}

\author{
Caroline Maris Takatu Tatiana Villas Boas Gabbi \\ Marcello Menta Simonsen Nico \\ Department of Dermatology, Medical School, University of São Paulo, São Paulo, Brazil
}

\section{Established Facts}

- It has been a matter of intense debate if lichen planus (LP) can be considered a "premalignant disorder," or if it can "transform" into squamous cell carcinoma.

- Ungual LP can lead to severe matrix and nail bed scarring.

\section{Novel Insights}

- The occurrence of squamous cell carcinoma (SCC) is very rare in ungual lichen planus (LP).

- SCC appearing in scars of LP can be considered a type of "Marjolin ulcer."

\section{Keywords}

Nails · Lichen planus · Verrucous carcinoma · Squamous cell carcinoma $\cdot$ Marjolin ulcer

\begin{abstract}
Background: Lichen planus (LP) can lead to severe scarring of the nail unit leading to anonychia. There are very few reports of squamous cell carcinoma (SCC) occurring in the lesions of ungual LP. Objective: The aim of this study was to revise the previously reported cases of SCC appearing in ungual LP and to present a new case. Methods: A PubMed search was performed with the terms "nail lichen planus" and "squamous cell carcinoma." Reported cases as well as a new case were depicted in a table. Results: Only 2 indexed
\end{abstract}

karger@karger.com www.karger.com/sad

Karger articles reporting 3 cases were found. All patients suffered of long-lasting scarring ungual LP. Conclusions: The occurrence of SCC in nail LP is rare. LP is not "premalignant" per se, but SCC might rarely arise in LP scars.

(ㄷ) 2020 S. Karger AG, Basel

\section{Introduction}

It has been a matter of intense debate if lichen planus (LP) can be considered a "premalignant disorder," or if it can "transform" into squamous cell carcinoma (SCC). Most publications on this topic come from the dental literature and study oral mucosal LP, on which SCC indeed at times issues [1]. Reports on SCC arising in cutaneous or ungual LP are scarce [2-4]. 



Fig. 1. A 56-year-old patient presented cicatricial anonychia of all twenty digits since childhood, possibly due to lichen planus. More recently, a verrucous mass on the left third distal phalanx and an erosive lesion on the left fifth finger developed (histopathology-large lesion: verrucous carcinoma, small lesion: in situ SCC) (a); detail of the tumor (b); X-ray showing distal phalanx mass with bone compromise (c). SCC, squamous cell carcinoma.

\section{Ungual LP and SCC}

Ungual LP is characterized by chronicity and tendency toward nail apparatus destruction. SCC appearing in lesions of ungual LP is very rarely described $[3,4]$. The characteristics of the 3 previously published cases, as well as a newly described case (Fig. 1,2), are included in Table 1. All patients presented nail LP for many years and showed severe nail destruction with scarring. One of the patients presented SCCs in 2 fingers. Our patient presented SCCs in 2 fingers and in 1 toe. All patients were treated with phalanx amputation. The in situ and the toe lesion of our patient were simply excised. SCCs can arise at areas of chronic and intense scarring such as burns, morphea, discoid lupus erythematosus, lupus vulgaris, epidermolysis bullosa dystrophica, hidradenitis, and nonhealing ulcers. The term "Marjolin ulcer" is classically used to designate SCCs that develop at the site of ancient scars and chronic wounds $[5,6]$.

Concerning the appearance of SCC in LP, most publications come from the dental literature and study oral mucosal LP, on which SCC indeed at times issues [1]. Interestingly, publications that deal with the matter of presence of SCC in lesions of oral LP do not mention the fact that this tumor only arises in lesions of ancient scarring LP. Since scarring in LP is much more common in the oral mucosal

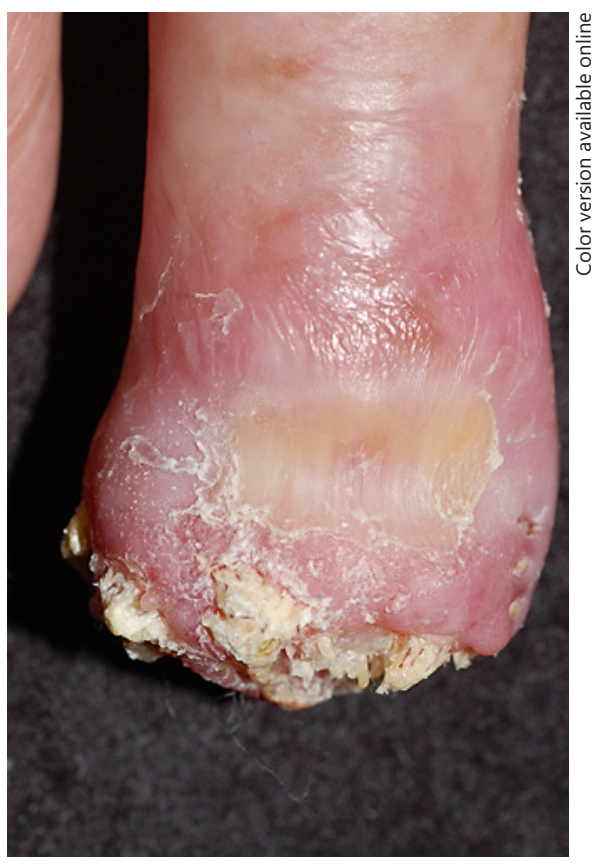

Fig. 2. Same patient as Fig. 1. Right second toe-cicatricial anonychia with associated keratotic and verrucous lesion. A verrucous carcinoma was detected on histopathology. 
Table 1. Published reports on SCC in patients affected by nail LP

\begin{tabular}{lllll}
\hline Case/author & $\begin{array}{l}\text { Sex/ } \\
\text { age }\end{array}$ & Location & Histopathology & Treatment \\
\hline Okiyama et al. [3] & M/51 & Left great toe & Invasive SCC & Amputation \\
\hline Costa et al. [4] & F/60 & Right third and fifth fingers & Invasive SCC & Amputation \\
\hline Costa et al. [4] & M/55 & Left great toe & Invasive SCC & Amputation \\
\hline Our patient & M/56 & $\begin{array}{l}\text { Left third and fifth fingers } \\
\text { Right second toe }\end{array}$ & $\begin{array}{l}\text { Third finger, and toe lesions: verrucous carcinoma } \\
\text { Small finger lesion: in situ SCC }\end{array}$ & $\begin{array}{l}\text { Large lesion: amputation } \\
\text { Small lesions: excision }\end{array}$ \\
\hline \multicolumn{2}{c}{ M, male; F, female; SCC, squamous cell carcinoma; LP, lichen planus. } &
\end{tabular}

than in cutaneous LP, it is not surprising that reports of SCC and LP are almost always at this site [1]. Other areas where LP might present with significant scarring include the vulva; SCC has been described to appear in such lesions [7]. Scarring in cutaneous LP is exceedingly rare since this presentation tends to be self-limited in the great majority of cases; SCC has been rarely described in rare cases of chronic, scarring cutaneous LP $[2,8]$.

The patient described by us possibly had developed an aggressive form of ungual LP in his childhood that led to anonychia of all digits. Anonychia in LP is due to intense nail matrix destruction leading to scarring, which manifests as loss of periungual folds and nail bed scarring. We strongly suspect, then, that the occurrence of SCC in LP follows the same unknown mechanisms by which the tumor may arise in other mucocutaneous scarring processes. In this sense, LP is not "premalignant" per se, and neither "transforms into SCC" as most publications state. On the other side, SCC may arise in ancient scars of LP as it may in many other scarring chronic diseases. In this sense, we believe that SCC in LP should be considered a type of "Marjolin ulcer." This patient presented 2 lesions diagnosed histopathologically as verrucous carcinomas, and a small in situ SCC. Verrucous carcinoma, a well-differentiated, slowly growing variant of SCC, is rarely described in LP lesions [9].

The oncogenic role of human papillomavirus (HPV) in SCC has been well established. The majority of digital SCC and SCC in situ occur on the periungual and/or subungual skin. HPV16, which is traditionally associated with lesions on mucosal surfaces, such as the cervix, is the most frequently involved high-risk HPV subtype in digital SCC [10]. The presence of HPV has not been searched in the previously reported cases of SCC appearing in nail LP or in our case; as stated above, we believe that this phenomenon is more related to the chronic scarring than with any HPV infection.

\section{Conclusions}

SCC can complicate LP; however, LP is not "premalignant" per se, and neither "transforms into SCC." SCC can rarely appear in ancient scars of LP, as it can in other scarring chronic diseases. This phenomenon is more commonly described in oral LP, but can very rarely occur in other forms of scarring LP such as genital and nail LP. In this sense, SCC in LP can be considered a type of "Marjolin ulcer."

\section{Statement of Ethics}

The patient gave written informed consent to publish the photos and details of this case. Research was conducted ethically in accordance with the World Medical Association Declaration of Helsinki.

\section{Conflict of Interest Statement}

The authors have no conflicts of interest to declare.

\section{Funding Sources}

The authors did not receive any funding.

\section{Author Contributions}

C.M.T.: writing of manuscript; T.V.B.G.: literature review and patient management; M.M.S.N.: idealization, final review and written patient consent (yes) and ethical approval (not obtained since this is a retrospective case report).
Takatu/Gabbi/Nico 


\section{References}

1 González-Moles MÁ, Warnakulasuriya S, González-Ruiz I, González-Ruiz L, Ayén Á, Lenouvel D, et al. Clinicopathological and prognostic characteristics of oral squamous cell carcinomas arising in patients with oral lichen planus: a systematic review and a comprehensive meta-analysis. Oral Oncology. 2020 Jul;106(1):104688.

2 Friedl TK, Flaig MJ, Ruzicka T, Rupec RA. Verruköses spinozelluläres karzinom auf Lichen ruber hypertrophicus. Drei Fallberichte mit literaturüberblick [Verrucous squamous cell carcinoma complicating hypertrophic lichen planus. Three case reports and review of the literature]. Hautarzt. 2011 Jan;62(1):40-5.
3 Okiyama N, Satoh T, Yokozeki H, Nishioka $\mathrm{K}$. Squamous cell carcinoma arising from lichen planus of nail matrix and nail bed. J Am Acad Dermatol. 2005 Nov;53(5):908-9.

4 Costa C, Villani A, Russo D, Cappello M, De Fata Salvatores G, Scalvenzi M. Squamous cell carcinomas in two cases of nail lichen planus: is there a real association? Dermatol Ther. 2018 Sep;8(3):491-4.

5 Bernstein SC, Lim KK, Brodland DG, Heidelberg KA. The many faces of squamous cell carcinoma. Dermatol Surg. 1996 Mar;22(3): 243-54.

6 Bazaliński D, Przybek-Mita J, Barańska B, Więch P. Marjolin's ulcer in chronic wounds: review of available literature. Contemp Oncol. 2017 Jun;21(3): 197-202.

7 Franck JM, Young AW Jr. Squamous cell carcinoma in situ arising within lichen planus of the vulva. Dermatol Surg. 1995 Oct;21(10): $890-4$.
8 Patel GK, Turner RJ, Marks R. Cutaneous lichen planus and squamous cell carcinoma. J Eur Acad Dermatol Venereol. 2003;17(1):98100.

9 Friedl TK, Flaig MJ, Ruzicka T, Rupec RA Verruköses spinozelluläres Karzinom auf Lichen ruber hypertrophicus. Drei fallberichte mit literaturüberblick [Verrucous squamous cell carcinoma complicating hypertrophic lichen planus. Three case reports and review of the literature]. Hautarzt. 2011 Jan;62(1):405.

10 Riddel C, Rashid R, Thomas V. Ungual and periungual human papillomavirus-associated squamous cell carcinoma: a review. J Am Acad Dermatol. 2011;64(6):1147-53. 